\title{
Characterization of Burnt Clays by X-ray Diffraction Analysis, Chemical Analysis and Environmental Scanning Electron Microscopy.
}

\author{
Eva Navrátilová ${ }^{1}$, Vilém Neděla ${ }^{1}$ \\ 1. Environmental Electron Microscopy Group, Institute of Scientific Instruments of the CAS, Brno, \\ Czech Republic
}

The article deals with the characterization of burnt clays (brick dust and bentonite) by determination of pozzolanic activity and content of amorphous phase. The presence of amorphous state in burnt clays was for the first time monitored by environmental scanning electron microscope.

Clays are mixtures of clay minerals (kaolinite, illite, montmorillonite and others) that are hydrated aluminosilicates from the chemical point of view. The clays also contain quartz, calcite, feldspars, micas, anatase and sulfides. The clay minerals are crystalline substances with a layered structure in which layers of $\mathrm{SiO}_{4}$ tetrahedrons and $\mathrm{AlO}_{6}$ octahedrons alternate [1]. Heat treatment (600 to $900{ }^{\circ} \mathrm{C}$ ) leads to dehydroxylation of clay minerals and the creation of the amorphous phases which are reactive and the calcined clays obtain pozzolanic activity [2-4]. The pozzolanic activity is an ability of pozzolans (silicate or aluminosilicate substances which themselves possess no binding ability) to react in the presence of water at normal temperature with calcium hydroxide to form hydration products. It can be determined as the amount of calcium oxide which is consumed in the reaction with pozzolan and by the reaction kinetics of the reaction $[2,5,6]$. The pozzolanic activity of the burnt clays is dependent on the content of amorphous phase. The pozzolanic activity increases with increasing amorphous phase content in the burnt clays. It significantly enhances the strength of modified lime mortars [7].

Brick dust and bentonite were selected as representatives of burnt clays. The brick dust burnt at a temperature $780{ }^{\circ} \mathrm{C}$ came from Libochovice (Heluz cihláŕský průmysl v. o. s.) as waste from the bricks grinding. The bentonite came from the localities Lutila Žiar nad Hronom (Keramost a. s.), it was burned at a temperature $840{ }^{\circ} \mathrm{C}$. The content of the amorphous phase was determined by evaluating records from a Bruker D8 diffractometer. The pozzolanic activity was determined via modified Chapelle test. Microstructure of the selected materials was studied on the dusts and also on the larger fractions. All samples were studied directly without sputtering and thus in the artefacts free state. It allows recognizing the presence of the amorphous phase whose distribution was monitored predominately. Environmental scanning electron microscope (ESEM) QUANTA 650 FEG (beam energy $10 \mathrm{keV}$, GSED detector, the water vapour pressure of $200 \mathrm{~Pa}$ ) was used.

Results of the pozzolanic activity and the content of amorphous phase of the burned clays are shown in Tab. 1. The table shows that the pozzolanic activity of the burned clays and thus their reactivity increases with the increasing amounts of amorphous phase in the burned clays. The microstructure of the brick dust is shown in Fig. 1. The amorphous phase cannot be identified in this figure. The microstructure of the brick fragment is shown in Fig. 2. In this case, the amorphous phase is just evident from this image. These images show that the amorphous phase of the burned clays can be identified only on the larger fragments of material. Treatment of the burnt clays into a fine fraction by grinding brick products or targeted milling leads to disruption of the amorphous phase unidentifiable in the fine dust. X-ray diffraction analysis provides information about the presence and quantity of the amorphous phase, 
environmental scanning electron microscopy provides information on the way of distribution and appearance of the amorphous phase. This work was supported by the project [8].

\section{References:}

[1] V Hanykýŕ et al, Acta Geodyn Geomater 6 (2009), p. 59.

[2] A Tironi et al, Cem Concr Com 37 (2013), p. 319.

[3] H Böke et al, Cem Concr Res 36 (2006), p. 1115.

[4] L Turanli et al, Cem Concr Res 33 (2003), p. 1539.

[5] A Askarinejad et al, Ultras Sonochem 19 (2012), p. 119.

[6] S Donatello et al, Cem Concr Com 32 (2010), p. 121.

[7] E Navrátilová et al, Constr Build Mater, submitted.

[8] The European Commission (ALISI No. CZ.1.05/2.1.00/01.0017)

\begin{tabular}{lll}
\hline & Brick dust & Bentonite \\
\hline Pozzolanic activity [mg Ca(OH)2/1 g pozzolan] & 460 & 972 \\
Amorphous phase content [\%] & 72.13 & 85.16 \\
\hline
\end{tabular}

Table 1. Pozzolanic activity and the amorphous phase content of the burnt clays
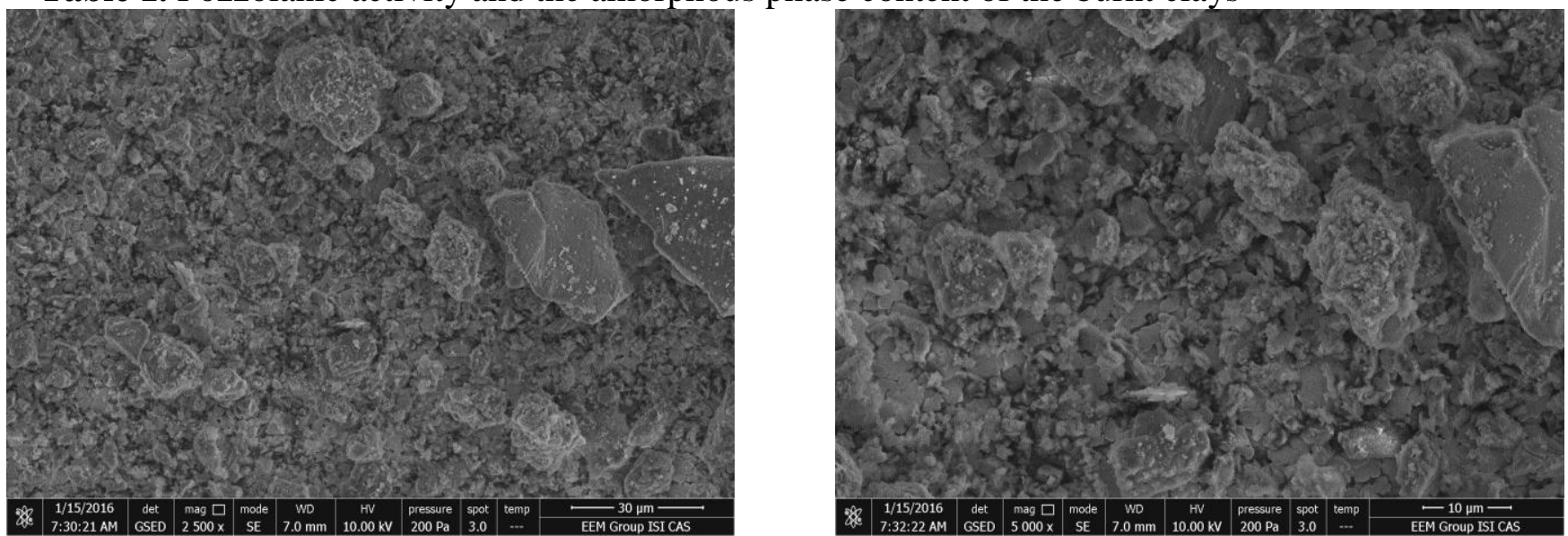

Figure 1. The ESEM image of the brick dust microstructure without the visible presence of the amorphous phase at a magnification $2500 \times$ and 5000×. Sputtered free sample, FEI QUANTA 650 FEG.
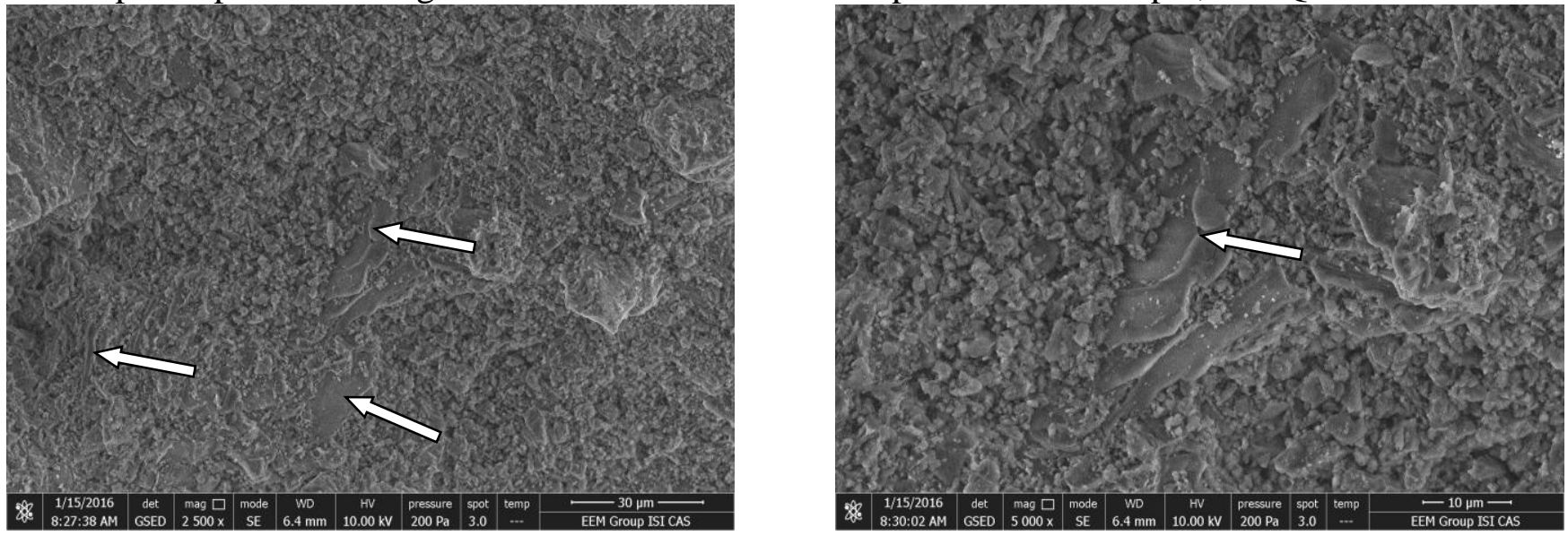

Figure 2. The ESEM micro image of the brick fraction with the visible areas of the amorphous phase at the same magnification as in Fig.1. Sputtered free sample, FEI QUANTA 650 FEG. 